\title{
Primary Extracranial Meningioma in Parotid Gland: Review of a Rare Case
}

\author{
Mukhopadhyay Sabuj G1* Datta Soma², Bandopadhyay Gautam ${ }^{3}$ \\ ${ }^{1 *}$ RMOCT, ${ }^{2}$ Assistant Professor, ${ }^{3 P}$ rofessor and Head, \\ Department of Pathology, Burdwan Medical College, Burdwan, West Bengal, India.
}

\begin{abstract}
Extracranial meningioma is a rare tumour that occurs in skin and soft tissue around scalp or along the vertebral axis. By definition they are not associated with an underlying meningioma of the neuraxis and extracranial extension of an intracranial tumour should always be excluded. Adult presentation of extracranial meningioma usually occurs in the vicinity of sensory organs (eye, ear, nose) or along the path of cranial and spinal nerves. 35 years, Male patient presented with unilateral swelling in right parotid region gradually increasing in size for last one year, without any other clinical symptom, clinically diagnosed as Mixed Parotid tumour. FNAC done from the swelling yielded particulate material, stained by routine MGG and PAP stain on dried and wet-fixed smears respectively, which on microscopy had shown high cellular yield of spindle to oval cells, epithelial looking (meningothelial cells), in syncytial clusters with whirling pattern, having central psammomatous calcification. Individual cells show blunt chromatin pattern, regular nuclear contour and presence of intra-nuclear cytoplasmic inclusions. On the basis of cytological findings, diagnosis of meningioma was given and subsequently computerized Tomography did not reveal
\end{abstract}

\section{INTRODUCTION}

Mostly arising in the vicinity of meninges, meningiomas are well known neoplasms presenting near the surface of the cerebral hemispheres or base of the brain. Though they can rarely present in intraventricular, intraparenchymal and intraosseous location inside the cranial cavity, primary extracranial meningioma is reported to be less than $2 \%$ of the total reported case of meningiomas. ${ }^{1}$ By definition they are not associated with an underlying meningioma of the neuraxis and extracranial extension of an intracranial tumour should always be excluded. Extracranial meningiomas occur mainly in the head neck region like orbital (i.e., optic sheath), glabellar, sinonasal, oropharyngeal or subgaleal locations. ${ }^{2}$ On the other hand cases from up to lungs and mediastinum have been reported. ${ }^{3}$

Intra cranial meningiomas (98\%) of cases are not accessible to an aspiration cytologist. Extracranial meningiomas, if encountered and aspirated, are usually misdiagnosed and culminating in mismanagement of such cases. Here we report a meningioma in the parotid gland which was diagnosed cytologically and confirmed by histopathology. neither any intracranial lesion, nor any intra-cranial / parapharyngeal extension. Final diagnosis of extra-cranial meningioma was confirmed by histopathological examination of the swelling. An FNAC finding of meningioma almost mimics its histopathological pattern and is therefore very much sensitive tool to diagnose the cases of extracranial meningioma.

Keywords: Meningioma, Extracranial, Soft tissue tumour.

\section{*Correspondence to:}

\section{Dr. Sabuj G. Mukhopadhyay,}

Quarters No. 13,

Doctors' Residences, Baburbag,

Burdwan Medical College, Burdwan., West Bengal, India.

Article History:

Received: 29-09-2016, Revised: 17-10-2016, Accepted: 28-11-2016

\begin{tabular}{|l|r|}
\hline \multicolumn{2}{|c|}{ Access this article online } \\
\hline Website: & Quick Response code \\
www.ijmrp.com & \\
\hline DOI: & \\
10.21276/jmrp.2016.2.6.034 & \\
\hline
\end{tabular}

\section{CASE PRESENTATION}

A healthy 35 years old South East Asian (Bengali) Male presented with a swelling in the right side of face for past one year. The swelling was painless, bore no relationship with eating and was slowly increasing in size for past 1 year. On examination, a 4 x 5 $\mathrm{cm} 2$ swelling with $2 \mathrm{~cm}$ elevation from skin surface was located just below the angle of the mandible. [Fig 1] The surface was smooth on inspection and it got prominent with clenching of teeth. On palpation, the surface was smooth, consistency firm, fluctuation negative and the borders were diffuse. The oral cavity was normal. Facial nerve function was normal (House-Brackmann grading system: Grade I). Patient was otherwise asymptomatic and routine bloodwork was unremarkable. He had no such swelling anywhere else in the body. Family history was noncontributory. A clinical diagnosis of Parotid mixed tumour was provided.

Fine Needle Aspiration (FNA) done from the swelling revealed a particulate aspirate which as stained with May Grunwald Giemsa (MGG) and Papanicolaou (PAP) stains in dry and wet - fixed 
smears respectively. On microscopy the smears were highly cellular. There was monomorphic spindle to oval, epithelial looking cells in sheets, small syncytial clusters and few discrete cells. A whirling pattern was very prominent among the cells. Foci of psammomatous calcification was appreciated in a number of clusters with epithelial looking cells (meningothelial cells) forming a whirling architecture around them. [Fig. 2-5]

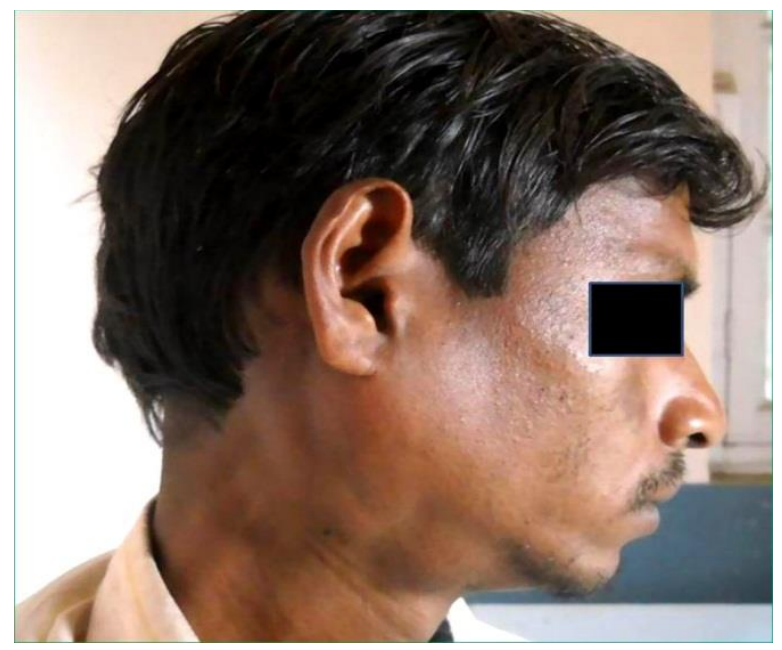

Fig 1: Swelling in Right Parotid region, 35/ M.

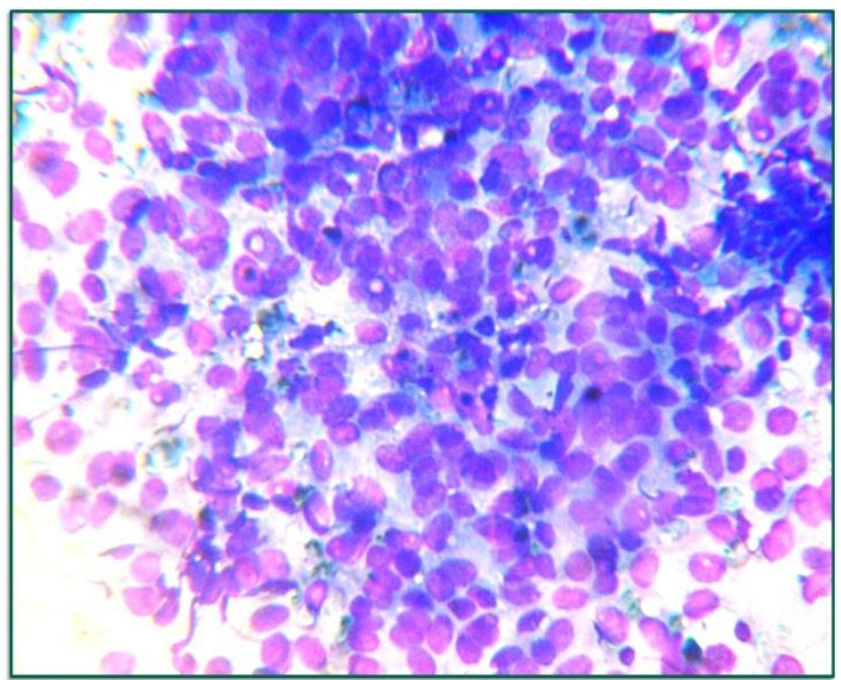

Fig 2: Leishman-Giemsa (LG) X 40 ; Dry-fixed FNAC smear showing high cellular yield of spindle to oval cells having blunt nuclear chromatin.

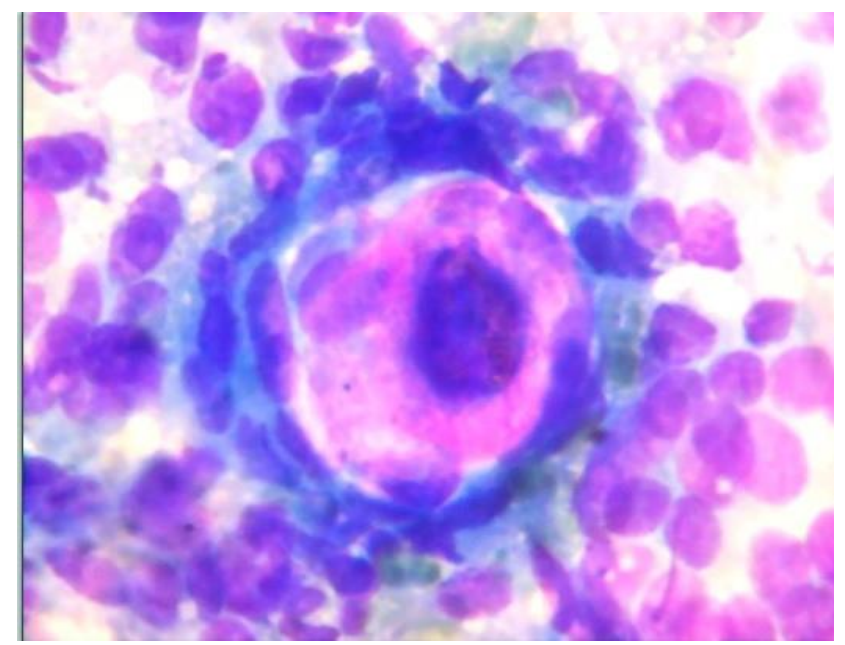

Fig 4: LG X 400 Cellular whorls having central Psammoma bodies
Individual cells show single oval nucleus, powdery chromatin pattern, a regular nuclear contour, intranuclear cytoplasmic inclusions, nuclear grooves at places [Fig 6] with pale cytoplasm and ill-defined cellular boundary (syncytial). On the basis of cytological findings, diagnosis of extracranial meningioma was given. Subsequent Computerized Tomography did not reveal neither any intracranial lesion, nor any intra-cranial / parapharyngeal extension.

A local excision of the lesion was performed under general anaesthesia and the specimen was sent for histopathological examination. A $4.5 \times 5.5 \times 2.5 \mathrm{~cm} 3$ whitish globular mass was received. It had a smooth surface. The consistency was firm. On cut section, a greyish white smooth surface was noted with no variegation. Representative sections were given. Routine Processing and Hematoxylin and Eosin (H\&E) staining revealed, a highly cellular tumour composed of sheets of meningothelial cells arranged in a whirling pattern with psammomatous calcification in some areas. Individual cells were spindle shaped, had a round nuclear contour and ill-defined syncytial cytoplasm. [Fig 7] Thus a final histopathological conclusive diagnosis of Meningioma in an extracranial location (parotid) was given.

The patient was followed up clinically for one year and no recurrence was reported.

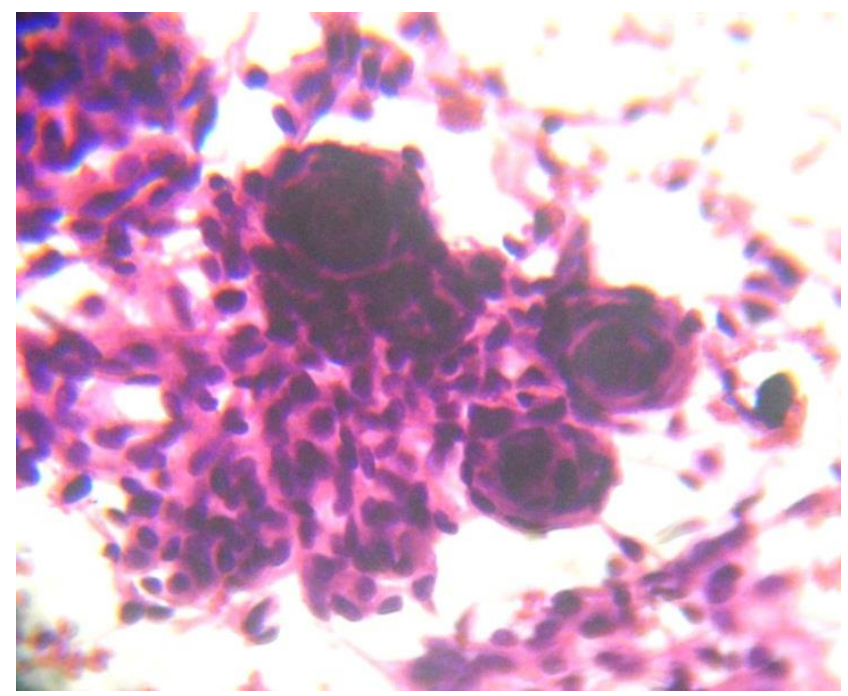

Fig 3: PAP X 40 Wet-fixed slide showing cellular smear having syncytial clusters with prominent whorling pattern and fair number of psammomatous calcification

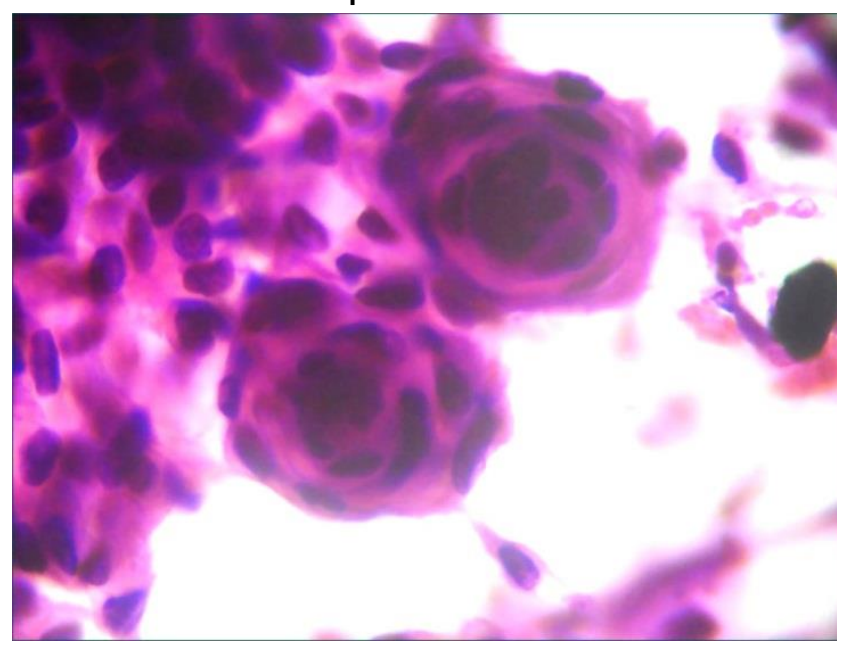

Fig 5: PAP X 400 Psammoma Bodies 


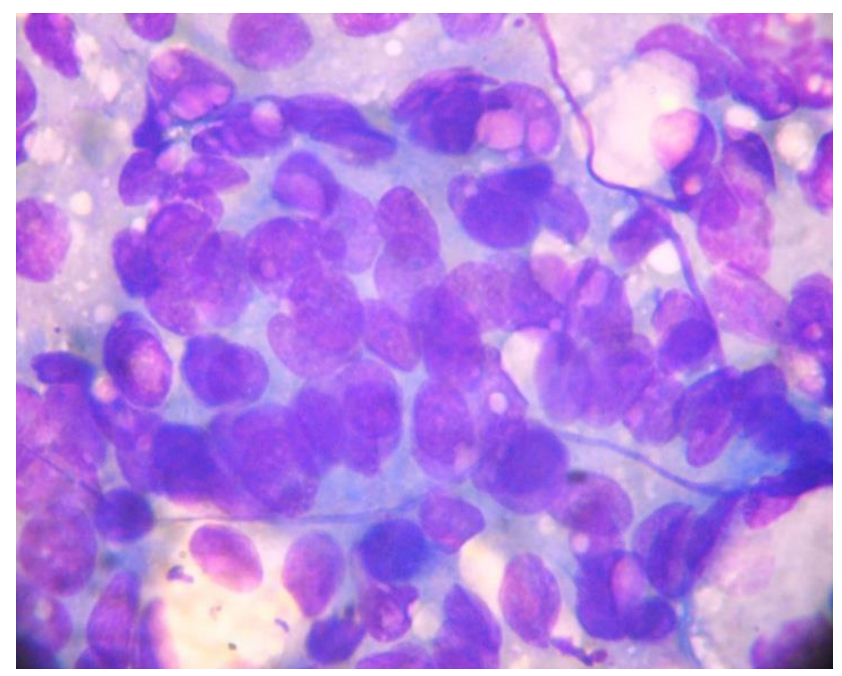

Fig 6: LG X 400 Intranuclear cytoplasmic inclusions

\section{DISCUSSION}

Meningiomas originate from meningocytes (arachnoid or meningothelial cells) capping the arachnoid villi. ${ }^{4}$ These multipotent mesenchymal cells may proliferate at the ectopic sites to form meningioma. ${ }^{5}$ These neoplasms are more common in females during the middle decades of life and account for $24-30 \%$ of primary intracranial tumors. ${ }^{6}$ Though rare, extracranial meningiomas are well recognized in literature with some large case series without any obvious predilection for sex in contrast with intracranial meningiomas which are female predominant. ${ }^{6}$ Extracranial Meningiomas are divided into four categories depending on their location. Type A Involves direct extension from a primary intracranial tumor through the foramina of the base of the skull. Type B involves extracranial growth from arachnoid cells within the sheaths of cranial nerves. Type $C$ involves extracranial growth from embryonic rests of arachnoid without any apparent connection to the foramina of the skull base or cranial nerves. They can happen anywhere in the body. Type $D$ involves distant metastases from intracranial meningioma. ${ }^{7}$ Our case was a Type $\mathrm{C}$, possibly arising from the embryonic cell rests in parotid region. Less than 1\% Extracranial meningiomas are malignant and Among the extracranial meningiomas $95 \%$ are meningothelial (WHO grade I) ${ }^{5}$

Extracranial meningioma is a diagnostic challenge for cytopathologist for two main reasons. Firstly, they are cohesive cellular tumours and yield of cells is usually poor to give a proper diagnosis, though in this case there is high cellularity. Secondly, it is easily forgotten in the list of differential diagnosis where Parotid Mixed Tumour, schwannoma, neurofibroma, paraganglioma or other benign and malignant salivary gland tumour are considered first. Such extracranial presentations are difficult to diagnose on CT and MRI also. ${ }^{8}$

Spindle cells in loose clusters, cell balls and whorls, and psammoma bodies, are recognized as diagnostic criteria for meningioma in cytology. The individual cells are described as pale ovoid or elongated nuclei with finely granular, evenly distributed chromatin with pale cytoplasm and indistinct cell borders. ${ }^{9}$ One should always rule out the above mentioned differential diagnoses before diagnosis of meningioma in a case of cervical or parotid region swelling. A diagnosis of extracranial meningioma should always be confirmed by histopathology. Immunohistochemistry for

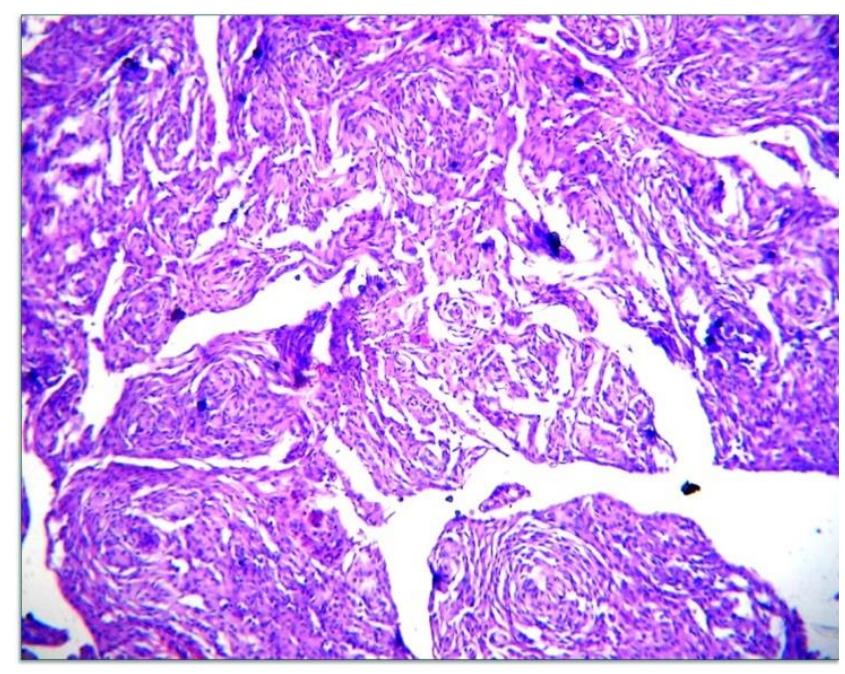

Fig 7: $\mathrm{H}$ and EX 40 sheets of meningothelial cells arranged in a whirling pattern

Vimentin and Epithelial Membrane Antigen (EMA) can help in a case of diagnostic confusion unlike our case where the cytology so totally reflects the histopathological features.

Surgical excision is the treatment of choice for extracranial meningiomas; completeness of surgical excision being the most important prognostic factor. Most of the cases do not recur. Radiation is considered in case of recurrent tumours.

To conclude, extracranial meningiomas should be considered in the differential diagnosis of tumours during FNA screening of tumors of head and neck region. The cytological and histological features correlate each other. Clinicians and pathologists should be aware of this rare diagnostic possibility.

\section{ACKNOWLEDGEMENT}

We are indebted to Staff and Faculty of Department of Pathology, Burdwan Medical College, West Bengal India for their support and time.

\section{ABBREVIATIONS}

FNA: Fine Needle Aspiration

MGG: May Grunwald Giemsa

PAP: Papanicolaou

H\&E: Hematoxylin and Eosin

CT: Computed Tomography

MRI: Magnetic Resonance Imaging

\section{REFERENCES}

1. Friedman $C D$, Costantino PD, Tietelbaum B, et al: Primary extracranial meningiomas of the head and neck. Laryngoscope 1990;100:41-48.

2. Thompson LD, Bouffard JP, Sandberg GD, Mena H. Primary ear and temporal bone meningiomas: a clinicopathologic study of 36 cases with a review of the literature. Mod Pathol 2003; 16 : 236-45.

3. Wilson AJ, Ratliff JL, Lagios MD, Aguilar MJ. Mediastinal meningioma. Am J Surg Pathol 1979;3:557-62.

4. Cushing, $\mathrm{H}$ : The meningiomas (dural endotheliomas): Their source, and favored seats of origin. Brain 1922;45:282-306.

5. Primary extracranial meningiomas: an analysis of 146 cases. Rushing EJ, Bouffard JP, McCall S, Olsen C, Mena H, Sandberg GD, Thompson LD. Head Neck Pathol 2009;3:116-30. 
6. Louis DN, Ohgaki H, Wiestler OD, Cavenee WK. World Health Organization classification of tumours of the central nervous system. 4th ed. Lyon: IARC Press; 2007.

7. Kumar S, Hasija S, Goyal R, Kataria SP, Sen R, Wadhera R. Ectopic parapharyngeal meningioma: diagnosis of a rare entity on FNAC. J Surg Case Rep. 2012; 2012 (12): rjs024. doi: 10.1093/jscr/rjs024.

8. Shetty C, Avinash KR, Auluck A, Mupparapu M. Extracranial meningioma of the parapharyngeal space: report of a case and review of the literature. Dentomaxillofacial Radiology 2007;36:117-20.

9. Orell RS, Klijanienko J. Head and neck; salivary glands. In: Orell RS, Sterrett GF, editors. Orrell and Sterrett's fine needle aspiration cytology. 5th ed. London: Churchill Livingstone; 2012. pp. 45.

\section{Source of Support: Nil. Conflict of Interest: None Declared.}

Copyright: () the author(s) and publisher. IJMRP is an official publication of Ibn Sina Academy of Medieval Medicine \& Sciences, registered in 2001 under Indian Trusts Act, 1882.

This is an open access article distributed under the terms of the Creative Commons Attribution Non-commercial License, which permits unrestricted non-commercial use, distribution, and reproduction in any medium, provided the original work is properly cited.

Cite this article as: Mukhopadhyay Sabuj G, Datta Soma, Bandopadhyay Gautam. Primary Extracranial Meningioma in Parotid Gland: Review of a Rare Case. Int J Med Res Prof. 2016; 2(6):163-66. DOI:10.21276/ijmrp.2016.2.6.034 